\title{
Challenges and opportunities for public health made possible by advances in natural language processing
}

\author{
Oliver Baclic ${ }^{1 *}$, Matthew Tunis ${ }^{1}$, Kelsey Young ${ }^{1}$, Coraline Doan², Howard Swerdfeger ${ }^{2}$, \\ Justin Schonfeld ${ }^{3 *}$
}

\begin{abstract}
Natural language processing (NLP) is a subfield of artificial intelligence devoted to understanding and generation of language. The recent advances in NLP technologies are enabling rapid analysis of vast amounts of text, thereby creating opportunities for health research and evidence-informed decision making. The analysis and data extraction from scientific literature, technical reports, health records, social media, surveys, registries and other documents can support core public health functions including the enhancement of existing surveillance systems (e.g. through faster identification of diseases and risk factors/at-risk populations), disease prevention strategies (e.g. through more efficient evaluation of the safety and effectiveness of interventions) and health promotion efforts (e.g. by providing the ability to obtain expert-level answers to any health related question). NLP is emerging as an important tool that can assist public health authorities in decreasing the burden of health inequality/ inequity in the population. The purpose of this paper is to provide some notable examples of both the potential applications and challenges of NLP use in public health.
\end{abstract}

This work is licensed under a Creative Commons Attribution 4.0 Internationa License.

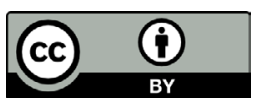

Affiliations

${ }^{1}$ Centre for Immunization and Respiratory Infectious Disease, Public Health Agency of Canada, Ottawa, ON

2 Data, Partnerships and Innovation Hub, Public Health Agency of Canada, Ottawa, ON

${ }^{3}$ National Microbiology Laboratory, Public Health Agency of Canada, Winnipeg, MB

\section{*Correspondence:}

oliver.baclic@canada.ca justin.schonfeld@canada.ca

Suggested citation: Baclic O, Tunis M, Young K, Doan C, Swerdfeger H, Schonfeld J. Challenges and
opportunities for public health made possible by advances in natural language processing. Can Commun Dis Rep 2020;46(6):161-8. https://doi.org/10.14745/ccdr.v46i06a02

Keywords: natural language processing, NLP, artificial intelligence, machine learning, public health

\section{Introduction}

There is a growing interest in deploying artificial intelligence (Al) strategies to achieve public health outcomes, particularly in response to the global coronavirus disease 2019 (COVID-19) pandemic where novel datasets, surveillance tools and models are emerging very quickly.

The objective of this manuscript is to provide a framework for considering natural language processing (NLP) approaches to public health based on historical applications. This overview includes a brief introduction to Al and NLP, suggests opportunities where NLP can be applied to public health problems and describes the challenges of applying NLP in a public health context. Particular articles were chosen to emphasize the breadth of potential applications for NLP in public health as well as the not inconsiderable challenges and risks inherent in incorporating AI/NLP in public health analysis and decision support.

\section{Artificial intelligence and natural language processing}

Al research has produced models that can interpret a radiograph $(1,2)$, detect irregular heartbeats using a smartwatch (3), automatically identify reports of infectious disease in the media (4), ascertain cardiovascular risk factors from retinal images (5) and find new targets for existing medications $(6,7)$. The success of these models is built from training on hundreds, thousands and sometimes millions of controlled, labelled and structured data points (8). The capacity of Al to provide constant, tireless and rapid analyses of data offers the potential to transform society's approach to promoting health and preventing and managing diseases. Al systems have the potential to "read" and triage all of the approximately 1.3 million research articles indexed by PubMed each year (9); "examine" comments from 1.5 billion Facebook users or "monitor" 500 million tweets of people struggling with mental illness on a daily basis, foodborne illness or the flu $(10,11)$; and simultaneously interact with each and every person seeking answers to their health questions, concerns, problems and challenges (12). 
NLP is a subfield of $A$ l that is devoted to developing algorithms and building models capable of using language in the same way humans do (13). It is routinely used in virtual assistants like "Siri" and "Alexa" or in Google searches and translations. NLP provides the ability to analyze and extract information from unstructured sources, automate question answering and conduct sentiment analysis and text summarization (8). With natural language (communication) being the primary means of knowledge collection and exchange in public health and medicine, NLP is the key to unlocking the potential of $\mathrm{Al}$ in biomedical sciences.

Most modern NLP platforms are built on models refined through machine learning techniques $(14,15)$. Machine learning techniques are based on four components: a model; data; a loss function, which is a measure of how well the model fits the data; and an algorithm for training (improving) the model (16). Recent breakthroughs in these areas have led to vastly improved NLP models that are powered by deep learning, a subfield of machine learning (17).

Innovation in the different types of models, such as recurrent neural network-based models (RNN), convolutional neural network-based models (CNN) and attention-based models, has allowed modern NLP systems to capture and model more complex linguistic relationships and concepts than simple word presence (i.e. keyword search) (18). This effort has been aided by vector-embedding approaches to preprocess the data that encode words before feeding them into a model. These approaches recognize that words exist in context (e.g. the meanings of "patient," "shot" and "virus" vary depending on context) and treat them as points in a conceptual space rather than isolated entities. The performance of the models has also been improved by the advent of transfer learning, that is, taking a model trained to perform one task and using it as the starting model for training on a related task. Hardware advancements and increases in freely available annotated datasets have also boosted the performance of NLP models. New evaluation tools and benchmarks, such as GLUE, superglue and BioASQ, are helping to broaden our understanding of the type and scope of information these new models can capture (19-21).

\section{Opportunities}

Public health aims to achieve optimal health outcomes within and across different populations, primarily by developing and implementing interventions that target modifiable causes of poor health (22-26). Success depends on the ability to effectively quantify the burden of disease or disease risk factors in the population and subsequently identify groups that are disproportionately affected or at-risk; identify best practices (i.e. optimal prevention or therapeutic strategies); and measure outcomes (27). This evidence-informed model of decision making is best represented by the PICO concept (patient/ problem, intervention/exposure, comparison, outcome). PICO provides an optimal knowledge identification strategy to frame and answer specific clinical or public health questions (28). Evidence-informed decision making is typically founded on the comprehensive and systematic review and synthesis of data in accordance with the PICO framework elements.

Today, information is being produced and published (e.g. scientific literature, technical reports, health records, social media, surveys, registries and other documents) at unprecedented rates. By providing the ability to rapidly analyze large amounts of unstructured or semistructured text, NLP has opened up immense opportunities for text-based research and evidence-informed decision making (29-34). NLP is emerging as a potentially powerful tool for supporting the rapid identification of populations, interventions and outcomes of interest that are required for disease surveillance, disease prevention and health promotion. For example, the use of NLP platforms that are able to detect particular features of individuals (population/ problem, e.g. a medical condition or a predisposing biological, behavioural, environmental or socioeconomic risk factor) in unstructured medical records or social media text can be used to enhance existing surveillance systems with real-world evidence. One recent study demonstrated the ability of NLP methods to predict the presence of depression prior to its appearance in the medical record (35). The ability to conduct real-time text mining of scientific publications for a particular PICO concept provides opportunities for decision makers to rapidly provide recommendations on disease prevention or management that are informed by the most current body of evidence when timely guidance is essential, such as during an outbreak. NLP-powered question-answering platforms and chatbots also carry the potential to improve health promotion activities by engaging individuals and providing personalized support or advice. Table 1 provides examples of potential applications of NLP in public health that have demonstrated at least some success.

\section{Challenges}

Despite the recent advances, barriers to widespread use of NLP technologies remain.

Similar to other Al techniques, NLP is highly dependent on the availability, quality and nature of the training data (72). Access and availability of appropriately annotated datasets (to make effective use of supervised or semi-supervised learning) are fundamental for training and implementing robust NLP models. For example, the development and use of algorithms that are able to conduct a systematic synthesis of published research on a particular topic or an analysis and data extraction from electronic health records requires unrestricted access to publisher or primary care/hospital databases. While the number of freely accessible biomedical datasets and pre-trained models has been increasing in recent years, the availability of those dealing with public health concepts remains limited (73). 
Table 1: Examples of existing and potential applications of natural language processing in public health

\begin{tabular}{|c|c|c|}
\hline $\begin{array}{l}\text { Type of } \\
\text { activity }\end{array}$ & $\begin{array}{l}\text { Public health } \\
\text { objective }\end{array}$ & Example of NLP use \\
\hline \multirow[t]{2}{*}{$\begin{array}{l}\text { Identification } \\
\text { of at-risk } \\
\text { populations or } \\
\text { conditions of } \\
\text { interest }\end{array}$} & $\begin{array}{l}\text { To continuously measure } \\
\text { the incidence and } \\
\text { prevalence of diseases } \\
\text { and disease risk factors } \\
\text { (i.e. surveillance) }\end{array}$ & $\begin{array}{l}\text { Analysis of unstructured } \\
\text { or semistructured text } \\
\text { from electronic health } \\
\text { records or social media } \\
(36-42)\end{array}$ \\
\hline & $\begin{array}{l}\text { To identify vulnerable and } \\
\text { at-risk populations }\end{array}$ & $\begin{array}{l}\text { Analysis of risk } \\
\text { behaviours using social } \\
\text { media (43-45) }\end{array}$ \\
\hline \multirow[t]{2}{*}{$\begin{array}{l}\text { Identification } \\
\text { of health } \\
\text { interventions }\end{array}$} & $\begin{array}{l}\text { To develop optimal } \\
\text { recommendations/ } \\
\text { interventions }\end{array}$ & $\begin{array}{l}\text { Automated systematic } \\
\text { review and analysis of the } \\
\text { information contained in } \\
\text { scientific publications and } \\
\text { unpublished data (46-50) }\end{array}$ \\
\hline & To identify best practices & $\begin{array}{l}\text { Identification of } \\
\text { promising public health } \\
\text { interventions through } \\
\text { analysis of online grey } \\
\text { and peer reviewed } \\
\text { literature (51) }\end{array}$ \\
\hline \multirow[t]{2}{*}{$\begin{array}{l}\text { Identification } \\
\text { of health } \\
\text { outcomes } \\
\text { using } \\
\text { real-world } \\
\text { evidence }\end{array}$} & $\begin{array}{l}\text { To evaluate the benefits } \\
\text { of health interventions }\end{array}$ & $\begin{array}{l}\text { Analysis of unstructured } \\
\text { or semistructured text } \\
\text { from electronic health } \\
\text { records, online media and } \\
\text { publications to determine } \\
\text { the impact of public } \\
\text { health recommendations } \\
\text { and interventions }(52,53)\end{array}$ \\
\hline & $\begin{array}{l}\text { To identify unintended } \\
\text { adverse outcomes related } \\
\text { to interventions }\end{array}$ & $\begin{array}{l}\text { Analysis of unstructured } \\
\text { or semistructured text } \\
\text { from electronic health } \\
\text { records, social media and } \\
\text { publications to identify } \\
\text { potential adverse events } \\
\text { of interventions (54-58) }\end{array}$ \\
\hline \multirow[t]{2}{*}{$\begin{array}{l}\text { Knowledge } \\
\text { generation } \\
\text { and translation }\end{array}$} & $\begin{array}{l}\text { To support public health } \\
\text { research }\end{array}$ & $\begin{array}{l}\text { Analysis and extraction } \\
\text { of information from } \\
\text { electronic health records } \\
\text { and scientific publications } \\
\text { for knowledge generation } \\
(59-62)\end{array}$ \\
\hline & $\begin{array}{l}\text { To support evidence- } \\
\text { informed decision making }\end{array}$ & $\begin{array}{l}\text { Use of chatbots, } \\
\text { question/answer systems } \\
\text { and text summarizers } \\
\text { to provide personalized } \\
\text { information to individuals } \\
\text { seeking advice to } \\
\text { improve their health and } \\
\text { prevent disease (63-65) }\end{array}$ \\
\hline \multirow[t]{2}{*}{$\begin{array}{l}\text { Environmental } \\
\text { scanning and } \\
\text { situational } \\
\text { awareness }\end{array}$} & $\begin{array}{l}\text { To conduct public } \\
\text { health risk assessments } \\
\text { and provide situational } \\
\text { awareness }\end{array}$ & $\begin{array}{l}\text { Analysis of online content } \\
\text { for real-time critical event } \\
\text { detection and mitigation } \\
(66-70)\end{array}$ \\
\hline & $\begin{array}{l}\text { To monitor activities that } \\
\text { may have an impact on } \\
\text { public health decision } \\
\text { making }\end{array}$ & $\begin{array}{l}\text { Analysis of decisions of } \\
\text { international and national } \\
\text { stakeholders (71) }\end{array}$ \\
\hline
\end{tabular}

Abbreviation: NLP, natural language processing
The ability to de-bias data (i.e. by providing the ability to inspect, explain and ethically adjust data) represents another major consideration for the training and use of NLP models in public health settings. Failing to account for biases in the development (e.g. data annotation), deployment (e.g. use of pre-trained platforms) and evaluation of NLP models could compromise the model outputs and reinforce existing health inequity (74). However, it is important to note that even when datasets and evaluations are adjusted for biases, this does not guarantee an equal impact across morally relevant strata. For example, use of health data available through social media platforms must take into account the specific age and socioeconomic groups that use them. A monitoring system trained on data from Facebook is likely to be biased towards health data and linguistic quirks specific to a population older than one trained on data from Snapchat (75). Recently many model agnostic tools have been developed to assess and correct unfairness in machine learning models in accordance with the efforts by the government and academic communities to define unacceptable Al development (76-81).

Currently, one of the biggest hurdles for further development of NLP systems in public health is limited data access $(82,83)$. Within Canada, health data are generally controlled regionally and, due to security and confidentiality concerns, there is reluctance to provide unhindered access to these systems and their integration with other datasets (e.g. data linkage). There have also been challenges with public perception of privacy and data access. A recent survey of social media users found that the majority considered analysis of their social media data to identify mental health issues "intrusive and exposing" and they would not consent to this (84).

Before key NLP public health activities can be realized at scale, such as the real-time analysis of national disease trends, jurisdictions will need to jointly determine a reasonable scope and access to public health-relevant data sources (e.g. health record and administrative data). In order to prevent privacy violations and data misuse, future applications of NLP in the analysis of personal health data are contingent on the ability to embed differential privacy into models (85), both during training and postdeployment. Access to important data is also limited through the current methods for accessing full text publications. Realization of fully automated PICO-specific knowledge extraction and synthesis will require unrestricted access to journal databases or new models of data storage (86).

Finally, as with any new technology, consideration must be given to assessment and evaluation of NLP models to ensure that they are working as intended and keeping in pace with society's changing ethical views. These NLP technologies need to be assessed to ensure they are functioning as expected and account for bias (87). Although today many approaches are posting equivalent or better-than-human scores on textual analysis tasks, it is important not to equate high scores with true language understanding. It is, however, equally important not to view 
a lack of true language understanding as a lack of usefulness. Models with a "relatively poor" depth of understanding can still be highly effective at information extraction, classification and prediction tasks, particularly with the increasing availability of labelled data.

\section{Natural language processing and the coronavirus disease 2019 (COVID-19)}

With the emergence of the COVID-19, NLP has taken a prominent role in the outbreak response efforts $(88,89)$. NLP has been rapidly employed to analyze the vast quantity of textual information that has been made available through unrestricted access to peer-review journals, preprints and digital media (90). NLP has been widely used to support the medical and scientific communities in finding answers to key research questions, summarization of evidence, question answering, tracking misinformation and monitoring of population sentiment (91-97).

\section{Conclusion}

NLP is creating extraordinary opportunities to improve evidenceinformed decision making in public health. We anticipate that broader applications of NLP will lead to the creation of more efficient surveillance systems that are able to identify diseases and at-risk conditions in real time. Similarly, with an ability to analyze and synthesize large volumes of information almost instantaneously, NLP is expected to facilitate targeted health promotion and disease prevention activities, potentially leading to population-wide disease reduction and greater health equity. However, these opportunities are not without risks: biased models, biased data, loss of data privacy and the need to maintain and update models to reflect the evolving language and context of public communication are all existing challenges that will need to be addressed. We encourage the public health and computer science communities to collaborate in order to mitigate these risks, ensure that public health practice does not fall behind in these technologies or miss opportunities for health promotion and disease surveillance and prevention in this rapidly evolving landscape.

\section{Authors' statement}

$\mathrm{OB}$ - Writing - original draft, review \& editing and conceptualization

MT - Writing - original draft, review \& editing and conceptualization

KY - Writing - review \& editing, and conceptualization

CD - Writing - review \& editing

HS - Writing - review \& editing

JS - Writing - original draft, review \& editing and

conceptualization

\section{Conflict of interest}

None.

\section{Acknowledgements}

We thank J Nash and J Robertson who were kind enough to offer feedback and suggestions.

\section{Funding}

This work is supported by the Public Health Agency of Canada. The research undertaken by JS was funded by the Canadian federal government's Genomic Research and Development Initiative.

\section{References}

1. Majkowska A, Mittal S, Steiner DF, Reicher JJ, McKinney SM, Duggan GE, Eswaran K, Cameron Chen PH, Liu Y, Kalidindi SR, Ding A, Corrado GS, Tse D, Shetty S. Chest radiograph interpretation with deep learning models: assessment with radiologist-adjudicated reference standards and population-adjusted evaluation. Radiology 2020;294(2):421-31. DOI PubMed

2. Liu X, Faes L, Kale A, Wagner SK, Fu DJ, Bruynseels A, Mahendiran T, Moraes G, Shamdas M, Kern C, Ledsam JR, Schmid MK, Balaskas K, Topol EJ, Bachmann LM, Keane PA, Denniston AK. A comparison of deep learning performance against health care professionals in detecting diseases from medical imaging: a systematic review and meta-analysis. Lancet Digital Health 2019. DOI

3. Perez MV, Mahaffey KW, Hedlin H, Rumsfeld JS, Garcia A, Ferris T, Balasubramanian V, Russo AM, Rajmane A, Cheung L, Hung G, Lee J, Kowey P, Talati N, Nag D, Gummidipundi SE, Beatty A, Hills MT, Desai S, Granger CB, Desai M, Turakhia MP; Apple Heart Study Investigators. Large-scale assessment of a smartwatch to identify atrial fibrillation. $N$ Engl J Med 2019;381(20):1909-17. DOl PubMed

4. Feldman J, Thomas-Bachli A, Forsyth J, Patel ZH, Khan K. Development of a global infectious disease activity database using natural language processing, machine learning, and human expertise. J Am Med Inform Assoc 2019;26(11):13559. DOI PubMed

5. Poplin R, Varadarajan AV, Blumer K, Liu Y, McConnell MV, Corrado GS, Peng L, Webster DR. Prediction of cardiovascular risk factors from retinal fundus photographs via deep learning. Nat Biomed Eng 2018;2(3):158-64. DOI PubMed

6. Vamathevan J, Clark D, Czodrowski P, Dunham I, Ferran E, Lee G, Li B, Madabhushi A, Shah P, Spitzer M, Zhao S. Applications of machine learning in drug discovery and development. Nat Rev Drug Discov 2019;18(6):463-77. DOI PubMed 
7. Corsello SM, Nagari RT, Spangler RD, Rossen J, Kocak M, Bryan JG, Humeidi R, Peck D, Wu X, Tang AA, Wang VM, Bender SA, Lemire E, Narayan R, Montgomery P, Ben-David U, Garvie CW, Chen Y, Rees MG, Lyons NJ, McFarland JM, Wong BT, Wang L, Dumont N, O'Hearn PJ, Stefan E, Doench JG, Harrington CN, Greulich $\mathrm{H}$, Meyerson M, Vazquez F, Subramanian A, Roth JA, Bittker JA, Boehm JS, Mader CC, Tsherniak A, Golub TR. Discovering the anticancer potential of non-oncology drugs by systematic viability profiling. Nat Can 2020;1:235-48. DOI

8. Topol EJ. High-performance medicine: the convergence of human and artificial intelligence. Nat Med 2019 Jan;25(1):44-56. DOI PubMed

9. MEDLINE PubMed Production Statistics. Bethesda (MD): U.S. National Library of Medicine (updated 2019-11-19; accessed 2020-01-27). https://www.nlm.nih.gov/bsd/ medline_pubmed_production_stats.html

10. Twitter usage statistics. Internet LiveStats.com (updated 2013-08-16; accessed 2020-01-27). https://www. internetlivestats.com/twitter-statistics/

11. Searching for health. Google News Lab, Schema; 2017 (accessed 2020-01-27). https://googlenewslab.gistapp.com/ searching-for-health

12. Friedman $C$, Elhadad N. Natural language processing in health care and biomedicine. In: Shortliffe E, Cimino J, editors. Biomed Informatics London: Springer; 2014. DOI

13. Ruder S. NLP-progress. London (UK): Sebastian Ruder (accessed 2020-01-18). https://nlpprogress.com/

14. Jurafsky D, Martin JH. Speech and language processing. Stanford (CA): Stanford University; 2019 (updated 201911-16; accessed 2020-01-18). https://web.stanford. edu/ jurafsky/slp3/

15. Nadkarni PM, Ohno-Machado L, Chapman WW. Natural language processing: an introduction. J Am Med Inform Assoc 2011;18(5):544-51. DOI PubMed

16. Nilsson N. Introduction to machine learning. Stanford (CA): Robotic Library, Department of Computer Science, Stanford University; 1998. http://robotics.stanford.edu/people/ nilsson/MLBOOK.pdf

17. Zhou M, Duan N, Liu S, Shum HY. Progress in neural NLP: modeling, learning, and reasoning. Engineering 2020;6(3):275-90. DOI

18. Tang B, Pan Z, Yin K, Khateeb A. Recent advances of deep learning in bioinformatics and computational biology. Front Genet 2019;10:214. DOI PubMed

19. Hirschberg J, Manning CD. Advances in natural language processing. Science 2015;349(6245):261-6. DOI PubMed

20. Wang A, Singh A, Michael J, Hill F, Levy O, Bowman S. GLUE: a multi-task benchmark and analysis platform for natural language understanding. Proceedings of the 2018 EMNLP Workshop BlackboxNLP: Analyzing and Interpreting Neural Networks for NLP. Brussels (BE): 2018 Nov; p. 353-5. $\mathrm{DOl}$
21. The Big Bad NLP Database. New York (NY): Quantum Stat; 2020 (updated 2020-01-21; accessed 2020-01-27). https:// quantumstat.com/dataset/dataset.html

22. Jackson B, Huston P. Advancing health equity to improve health: the time is now. Health Promot Chronic Dis Prev Can 2016;36(2):17-20. DOI PubMed

23. Pan American Health Organization. Just societies: health equity and dignified lives. Report of the Commission of the Pan American Health Organization on Equity and Health Inequalities in the Americas. Washington (DC): Pan American Health Organization (updated 2019-11; accessed 2020-0118). http://search.ebscohost.com/login.aspx?direct=true\&sit

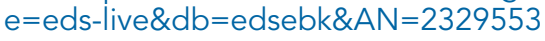

24. Marmot M, Allen J, Goldblatt P, Boyce T, McNeish D, Grady M, Geddes I; The Marmot Review. Fair society, healthy lives: strategic review of health inequalities in England post-2010. UCL Institute of Health Equity.

http://www.parliament.uk/documents/fair-society-healthy-live s-full-report.pdf

25. Arcaya MC, Arcaya AL, Subramanian SV. Inequalities in health: definitions, concepts, and theories. Glob Health Action 2015;8:27106. DOl PubMed

26. Public Health Agency of Canada. The Chief Public Health Officer's report on the state of public health in Canada: addressing health inequalities. Ottawa (ON): Public Health Agency of Canada; 2008. Report No.: HP2-10/2008E. http://www.phac-aspc.gc.ca/cphorsphc-respcacsp/2008/fr-rc/ index-eng.ph

27. Ndumbe-Eyoh S, Dyck L, Clement C. Common agenda for public health action on health equity. Antigonish (NS): National Collaborating Centre for Determinants of Health, St Francis Xavier University; 2016. http://nccdh.ca/images/ uploads/comments/Common_Agenda_EN.pdf

28. Alonso-Coello P, Schünemann HJ, Moberg J, Brignardello-Petersen R, Akl EA, Davoli M, Treweek S, Mustafa RA, Rada G, Rosenbaum S, Morelli A, Guyatt GH, Oxman AD; GRADE Working Group. GRADE Evidence to Decision (EtD) frameworks: a systematic and transparent approach to making well informed healthcare choices. 1: Introduction. BMJ 2016;353:i2016. DOI PubMed

29. Kim ES, James P, Zevon ES, Trudel-Fitzgerald C, Kubzansky LD, Grodstein F. Social media as an emerging data resource for epidemiologic research: characteristics of social media users and non-users in the Nurses' Health Study II. Am J Epidemiol 2020;189(2):156-61. DOI PubMed

30. Koleck TA, Dreisbach C, Bourne PE, Bakken S. Natural language processing of symptoms documented in free-text narratives of electronic health records: a systematic review. J Am Med Inform Assoc 2019;26(4):364-79. DOI PubMed

31. Marshall IJ, Wallace BC. Toward systematic review automation: a practical guide to using machine learning tools in research synthesis. Syst Rev 2019;8(1):163. DOI PubMed 
32. Yin Z, Sulieman LM, Malin BA. A systematic literature review of machine learning in online personal health data. J Am Med Inform Assoc 2019;26(6):561-76. DOI PubMed

33. Kreimeyer K, Foster M, Pandey A, Arya N, Halford G, Jones SF, Forshee R, Walderhaug M, Botsis T. Natural language processing systems for capturing and standardizing unstructured clinical information: A systematic review. J Biomed Inform 2017;73:14-29. DOI PubMed

34. The Office of the National Coordinator for Health Information Technology. Health IT dashboard: Quick stats. Washington (DC): U.S. Department of Health and Human Services. https://dashboard.healthit.gov/quickstats/ quickstats.php

35. Harris JK, Mansour R, Choucair B, Olson J, Nissen C, Bhatt J; Centers for Disease Control and Prevention. Health department use of social media to identify foodborne illness - Chicago, Illinois, 2013-2014. MMWR Morb Mortal Wkly Rep 2014;63(32):681-5. PubMed

36. Gesualdo F, Stilo G, Agricola E, Gonfiantini MV, Pandolfi E, Velardi P, Tozzi AE. Influenza-like illness surveillance on Twitter through automated learning of naïve language. PLoS One 2013;8(12):e82489. DOI PubMed

37. Eichstaedt JC, Smith RJ, Merchant RM, Ungar LH, Crutchley P, Preoțiuc-Pietro D, Asch DA, Schwartz HA. Facebook language predicts depression in medical records. Proc Natl Acad Sci USA. 2018;115(44):11203-8. DOI

38. Şerban O, Thapen N, Maginnis B, Hankin C, Foot V. Real-time processing of social media with SENTINEL: a syndromic surveillance system incorporating deep learning for health classification. Inf Process Manage 2019;56(3):1166-84. DOI

39. Edo-Osagie O, Smith G, Lake I, Edeghere O, De La Iglesia B. Twitter mining using semi-supervised classification for relevance filtering in syndromic surveillance. PLoS One 2019;14(7):e0210689. DOI PubMed

40. Ford E, Carroll JA, Smith HE, Scott D, Cassell JA. Extracting information from the text of electronic medical records to improve case detection: a systematic review. J Am Med Inform Assoc 2016;23(5):1007-15. DOl PubMed

41. Dorr D, Bejan CA, Pizzimenti C, Singh S, Storer M, Quinones $A$. Identifying patients with significant problems related to social determinants of health with natural language processing. Stud Health Technol Inform 2019;264:1456-7. DOI PubMed

42. Carrell DS, Cronkite D, Palmer RE, Saunders K, Gross DE, Masters ET, Hylan TR, Von Korff M. Using natural language processing to identify problem usage of prescription opioids. Int J Med Inform 2015;84(12):1057-64. DOI PubMed

43. Cacheda F, Fernandez D, Novoa FJ, Carneiro V. Early detection of depression: social network analysis and random forest techniques. J Med Internet Res 2019;21(6):e12554. DOI PubMed
44. Conway M, Hu M, Chapman WW. Recent advances in using natural language processing to address public health research questions using social media and consumer generated data. Yearb Med Inform 2019;28(1):208-17. DOl PubMed

45. Coppersmith G, Dredze M, Harman C. Quantifying mental health signals in Twitter. Proceedings of the Workshop on Computational Linguistics and Clinical Psychology: from linguistic signal to clinical reality. Baltimore (MA): 27 June 2014;p. 51-60. DOI

46. Gates A, Guitard S, Pillay J, Elliott SA, Dyson MP, Newton AS, Hartling L. Performance and usability of machine learning for screening in systematic reviews: a comparative evaluation of three tools. Syst Rev 2019;8(1):278. DOI PubMed

47. Przybyła P, Soto AJ, Ananiadou S. Identifying personalised treatments and clinical trials for precision medicine using semantic search with Thalia. Manchester (UK): TREC; 2017. https://www.researchgate.net/publication/323629465 Identifying_Personalised_Treatments_and_Clinical_Trials_for_ Precision_Medicine_using_Semantic_Search_with_Thalia

48. Bannach-Brown A, Przybyła P, Thomas J, Rice AS, Ananiadou S, Liao J, Macleod MR. Machine learning algorithms for systematic review: reducing workload in a preclinical review of animal studies and reducing human screening error. Syst Rev 2019;8(1):23. DOI PubMed

49. Norman C, Leeflang M, Spijker R, Kanoulas E, Névéol A. A distantly supervised dataset for automated data extraction from diagnostic studies. ACL Workshop on Biomedical Natural Language Processing, Florence (IT): 2019 Aug. DOI

50. Tsafnat G, Glasziou P, Karystianis G, Coiera E. Automated screening of research studies for systematic reviews using study characteristics. Syst Rev 2018;7(1):64. DOI PubMed

51. Lerner I, Créquit $P$, Ravaud $P$, Atal I. Automatic screening using word embeddings achieved high sensitivity and workload reduction for updating living network meta-analyses. J Clin Epidemiol 2019;108:86-94. DOI PubMed

52. Tucker TC, Durbin EB, McDowell JK, Huang B. Unlocking the potential of population-based cancer registries. Cancer 2019;125(21):3729-37. DOl PubMed

53. Mohammadhassanzadeh $\mathrm{H}$, Sketris I, Traynor R, Alexander S, Winquist $B$, Stewart SA. Using natural language processing to examine the uptake, content, and readability of media coverage of a pan-Canadian drug safety research project: cross-sectional observational study. JMIR Form Res 2020;4(1):e13296. DOI PubMed

54. Banerji A, Lai KH, Li Y, Saff RR, Camargo CA Jr, Blumenthal KG, Zhou L. Natural language processing combined with ICD-9-CM codes as a novel method to study the epidemiology of allergic drug reactions. J Allergy Clin Immunol Pract 2020;8(3):1032-1038.e1. DOI PubMed 
55. Young IJ, Luz S, Lone N. A systematic review of natural language processing for classification tasks in the field of incident reporting and adverse event analysis. Int J Med Inform 2019;132:103971. DOI PubMed

56. Henry S, Buchan K, Filannino M, Stubbs A, Uzuner O. 2018 $\mathrm{n} 2 \mathrm{c} 2$ shared task on adverse drug events and medication extraction in electronic health records. J Am Med Inform Assoc 2020;27(1):3-12. DOI PubMed

57. Fan B, Fan W, Smith C, Garner H. Adverse drug event detection and extraction from open data: a deep learning approach. Inf Process Manage 2020;57(1):102131. DOI

58. Yu W, Zheng C, Xie F, Chen W, Mercado C, Sy LS, Qian L, Glenn S, Tseng HF, Lee G, Duffy J, McNeil MM, Daley MF, Crane B, McLean HQ, Jackson LA, Jacobsen SJ. The use of natural language processing to identify vaccine-related anaphylaxis at five health care systems in the Vaccine Safety Datalink. Pharmacoepidemiol Drug Saf 2020;29(2):182-8. DOI PubMed

59. Liu F, Weng C, Yu H. Advancing clinical research through natural language processing on electronic health records: traditional machine learning meets deep learning. In: Richesson RL, Andrews JE, editors: Clinical Research Informatics. Springer International Publishing; 2019. p. 357-78. DOl

60. Chan L, Beers K, Yau AA, Chauhan K, Duffy Á, Chaudhary K, Debnath N, Saha A, Pattharanitima P, Cho J, Kotanko P, Federman A, Coca SG, Van Vleck T, Nadkarni GN. Natural language processing of electronic health records is superior to billing codes to identify symptom burden in hemodialysis patients. Kidney Int 2020;97(2):383-92. DOI PubMed

61. Juhn Y, Liu H. Artificial intelligence approaches using natural language processing to advance EHR-based clinical research. J Allergy Clin Immunol 2020;145(2):463-9. DOI PubMed

62. Wang $Y$, Wang L, Rastegar-Mojarad M, Moon $S$, Shen $F$, Afzal N, Liu S, Zeng Y, Mehrabi S, Sohn S, Liu H. Clinical information extraction applications: A literature review. J Biomed Inform 2018;77:34-49. DOI PubMed

63. Laranjo L, Dunn AG, Tong HL, Kocaballi AB, Chen J, Bashir R, Surian D, Gallego B, Magrabi F, Lau AY, Coiera E. Conversational agents in healthcare: a systematic review. J Am Med Inform Assoc 2018;25(9):1248-58. DOI PubMed

64. Head to health. COVID-19 support. Department of Health; Australian Government (accessed 2020-01-27). https://headtohealth.gov.au/sam-the-chatbot

65. Pereira J, Díaz Ó. Using health chatbots for behavior change: a mapping study. J Med Syst 2019;43(5):135. DOI PubMed

66. Dion M, AbdelMalik P, Mawudeku A. Big Data and the Global Public Health Intelligence Network (GPHIN). Can Commun Dis Rep 2015;41(9):209-14. DOI PubMed
67. Ghosh S, Chakraborty P, Lewis BL, Majumder M, Cohn E, Brownstein JS, Marathe M, Ramakrishnan N. GELL: Automatic extraction of epidemiological line lists from open sources. Proceedings of the 23rd ACM SIGKDD International Conference on Knowledge Discovery and Data Mining; 2017 Aug 13-17; Halifax (NS): Association for Computing Machinery; 2017. p. 1477-86. DOI

68. Charles-Smith LE, Reynolds TL, Cameron MA, Conway M, Lau EH, Olsen JM, Pavlin JA, Shigematsu M, Streichert LC, Suda KJ, Corley CD. Using social media for actionable disease surveillance and outbreak management: a systematic literature review. PLoS One 2015;10(10):e0139701. DOI PubMed

69. Jordan S, Hovet S, Fung I, Liang H, Fu KW, Tsz Ho Tse Z. Using Twitter for public health surveillance from monitoring and prediction to public response. Data (Basel) 2018;4(1):6. $\mathrm{DOI}$

70. Abbood A, Ullrich A, Busche R, Ghozzi S. EventEpi-A natural language processing framework for event-based surveillance medRxiv 2019;19006395. DOI

71. Anglin K. Gather-narrow-extract: A framework for studying local policy variation using web-scraping and natural language processing. J Res Educ Eff 2019;12(4):685-706. $\mathrm{DOI}$

72. Tatman R, Conner K. Effects of talker dialect, gender \& race on accuracy of Bing speech and YouTube automatic captions. Proc Interspeech 2017;934-8. DOI

73. Spasic I, Nenadic G. Clinical text data in machine learning: systematic review. JMIR Med Inform 2020;8(3):e17984. DOI PubMed

74. Rajkomar A, Hardt M, Howell MD, Corrado G, Chin MH. Ensuring fairness in machine learning to advance health equity. Ann Intern Med 2018;169(12):866-72. DOI PubMed

75. Gramlich J. 10 facts about Americans and Facebook. Washington (DC): Pew Research Center (accessed 202001-27). https://www.pewresearch.org/fact-tank/2019/05/16/ facts-about-americans-and-facebook/

76. Xu C, Doshi T. Fairness indicators: scalable infrastructure for fair ML system. Mountain View (CA): Google (accessed 2020-01-27). DOI

77. Holstein K, Vaughan JW, Daumé H, Dudík M, Wallach H. Improving fairness in machine learning systems: What do industry practitioners need? $\mathrm{CHI}$ ८19: Proceedings of the $2019 \mathrm{CHI}$ Conference on Human Factors in Computing Systems. 2019 Paper No.: 600. p. 1-16. DOI

78. Wiens J, Price WN 2nd, Sjoding MW. Diagnosing bias in data-driven algorithms for healthcare. Nat Med 2020;26(1):25-6. DOI PubMed

79. Chen IY, Joshi S, Ghassemi M. Treating health disparities with artificial intelligence. Nat Med 2020;26(1):16-7. DOl PubMed 
80. Montreal Declaration for a Responsible Development of Artificial Intelligence. Forum on the Socially Responsible Development of Al: 2017 Nov 2-3: Montréal (QC) (accessed 2020-01-18). https://www.montrealdeclaration-responsibleai. com/the-declaration

81. Treasury Board Secretariat. Directive on automated decision-making. Ottawa (ON): Government of Canada (modified 2019-02-05; accessed 2020-01-27). https://www. tbs-sct.gc.ca/pol/doc-eng.aspx?id=32592

82. Friedman C, Rindflesch TC, Corn M. Natural language processing: state of the art and prospects for significant progress, a workshop sponsored by the National Library of Medicine. J Biomed Inform 2013;46(5):765-73. DOI PubMed

83. Sheikhalishahi S, Miotto R, Dudley JT, Lavelli A, Rinaldi F, Osmani V. Natural language processing of clinical notes on chronic diseases: systematic review. JMIR Med Inform 2019;7(2):e12239. DOl PubMed

84. Ford E, Curlewis K, Wongkoblap A, Curcin V. Public opinions on using social media content to identify users with depression and target mental health care advertising: mixed methods survey. JMIR Ment Health 2019;6(11):e12942.

DOI PubMed

85. Radebaugh $\mathrm{C}$, Erlingsson U. Introducing tensorflow privacy: learning with differential privacy for training data. Medium. com (accessed 2020-01-27). https://medium.com/tensorflow/ introducing-tensorflowprivacy-learning-with-differential -privacy-for-trainingdata-b143c5e801b6

86. Penning de Vries BB, van Smeden M, Rosendaal FR, Groenwold RH. Title, abstract, and keyword searching resulted in poor recovery of articles in systematic reviews of epidemiologic practice. J Clin Epidemiol 2020;121:55-61. DOI PubMed

87. Obermeyer Z, Powers B, Vogeli C, Mullainathan S. Dissecting racial bias in an algorithm used to manage the health of populations. Science 2019;366(6464):447-53. DOI PubMed
88. Coronavirus tech handbook: natural language processing. https://coronavirustechhandbook.com/nlp

89. COVID-19 Open Research Dataset Challenge (CORD-19): An Al challenge with AI2, CZI, MSR, Georgetown, NIH \& The White House. San Francisco (CA): kaggle.com (accessed 2020-01-27). https://www.kaggle.com/allen-institute-for-ai/ CORD-19-research-challenge

90. PubMed Central. Public Health Emergency COVID-19 Initiative. Bethesda (MD): US National Library of Medicine (accessed 2020-01-27). PubMed

91. Bullock J, Luccioni A, Pham KH, Lam CS, Luengo-Oroz M. Mapping the landscape of artificial intelligence applications against COVID-19. arXiv:2003.11336 [cs.CY]. https://vectorinstitute.ai/wp-content/uploads/2020/03/ arxiv-mappingai.pdf

92. Allen Institute for Artificial Intelligence (AI2). CORD-19 Explorer: explore the dataset. https://cord-19.apps.allenai. org/

93. Chen E, Lerman K, Ferrara E. COVID-19: the first public coronavirus Twitter dataset. Ithaca (NY): Cornell University (accessed 2020-01-27). https://arix.org/abs/2003.07372

94. LitCovid. Bethesda (MD): U.S. National Library of Medicine (accessed 2020-01-27). PubMed

95. Coronafiles: Chatbots take strain off Denmark's emergency helplines (accessed 2020-01-27). https://sifted.eu/articles/ coronafiles-chatbots-helplines/

96. Kritikos M. At a glance: scientific foresight: What if we could fight coronavirus with artificial intelligence? Scientific Foresight Unit, European Parliament. https://www.europarl. europa.eu/RegData/etudes/ATAG/2020/641538/EPRS_ ATA(2020)641538_EN.pdf

97. Against Al. COVID-19 Canada. About us. Toronto (ON): CIFAR (accessed 2020-01-27). https://ai-against-covid.ca/ 